\title{
Decision Support for an Optimal Choice of Subsidised Routes in Air Transportation
}

Alan Kinene, Tobias Andersson Granberg, Valentin Polishchuk and Clas Rydergren

The self-archived postprint version of this journal article is available at Linköping University Institutional Repository (DiVA):

http:/ / urn.kb.se/ resolve?urn=urn:nbn:se:liu:diva-162916

N.B.: When citing this work, cite the original publication.

Kinene, A., Andersson Granberg, T., Polishchuk, V., Rydergren, C., (2020), Decision Support for an Optimal Choice of Subsidised Routes in Air Transportation, J ournal of Air Transport Management, 82, 101724. https:// doi.org/ 10.1016/j.jairtraman.2019.101724

Original publication available at:

https:/ / doi.org/ 10.1016/j.jairtraman.2019.101724

Copyright: Elsevier

http:// www.elsevier.com/

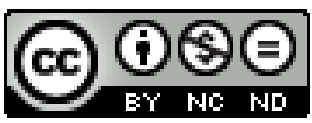




\title{
Decision Support for an Optimal Choice of Subsidised Routes in Air Transportation
}

\author{
Alan Kinene ${ }^{a}$, Tobias Andersson Granberg ${ }^{a}$, Valentin Polishchuk ${ }^{a}$ and \\ Clas Rydergren $^{a}$ \\ ${ }^{a}$ Div. Communication and Transport Systems, ITN, Linköping University Norrköping, Sweden
}

\section{ARTICLE INFO}

Keywords:

Decision Support

Public Service Obligation

Maximum Coverage

Air Transportation

Demand Estimation

\begin{abstract}
A B S TR ACT
The aim of the work presented here is to develop a mathematical model that can assist decision-makers in selecting the optimal network of subsidised routes in air transportation. Sweden is used as a case study. The results show that even if most of the Swedish population already has a good accessibility, the model can suggest new routes that can further improve accessibility without increasing the subsidisation cost. The closure of an airport reduces the available commercial routes, which would impair the accessibility to a given destination; a subsidised route would hence be required as a replacement. The ability of the model to consider several accessibility criteria makes it useful for managers at transportation authorities when making airport location decisions.
\end{abstract}

\section{Introduction}

The deregulation of air transportation (1978 and 1987 in the United States and Europe, respectively) gave airlines the liberty to choose new profitable routes to operate and consequently to abandon the unprofitable ones. Therefore, routes with insufficient passenger demand, although crucial in regional economic development, are often ignored by airlines (Morrison and Winston, 2010; Williams and Bråthen, 2012). In reaction, countries adopted subsidy schemes to guarantee accessibility to and from small communities or regions with insufficient demand for commercial air services. Examples of subsidy schemes include the Public Service Obligation (PSO) provided by countries in the European Economic Area (EEA), and the Essential Air Service (EAS) program in the United States. Subsidy schemes provide scheduled air services in communities where commercial air services are considered unprofitable by airlines. Additionally, they aim to link a target community to a potential destination such as a hub airport or a major city. However, the subsidy schemes are characterised by critics for underutilisation of the routes and disproportional cost of subsidisation.

The subsidy schemes aim to achieve an efficient air transportation network and this involves making decisions about which routes to subsidise, with respect to defined criteria and the available budget. Defining a criterion avoids ad-hoc decision-making by the authorities, eliminates wasteful resource allocation through inefficient transportation networks and is used as a foundation for efficient transportation service provision (Bråthen and Eriksen, 2016).

\subsection{Criteria and targets}

Examples of defined criteria are accessibility to a) a major city, b) advanced health care, c) a hub or an international airport, d) a university, or e) a tourist site. The criteria are usually specified as travel time-related targets. For example, it should be possible to access a capital city within four hours. There are variations in how these subsidy schemes are implemented because countries use different assessment methods for defining the subsidy scheme criteria and their associated targets. This is very evident among the EEA member states despite of the European regulations (EU Regulation, 2008)

\footnotetext{
${ }^{\star}$ This research is part of the Sustainable Location of Airports (SAILAS) project that is funded by the Swedish Transport Administration (Trafikverket).

@alan.kinene@liu.se ( Alan Kinene); tobias.andersson.granberg@liu.se ( Tobias Andersson Granberg); valentin.polishchuk@liu.se (Valentin Polishchuk); clas.rydergren@liu.se ( Clas Rydergren) ORCID(s):
} 
that suggest a unified implementation of the subsidy scheme (PSO scheme) (Williams and Pagliari, 2004).

Apart from the criteria and the associated targets, there may also be other requirements on the subsidised routes. According to Bråthen and Eriksen (2016); Williams (2010), commonly used requirements on PSO routes are: (1) minimum number of round trips per day; (2) minimum seat capacity per day; (3) maximum number of stops; (4) time table requirements, for example, maximum number of days per year with no service; (5) size of aircraft; (6) air emissions of specified substances; and (7) maximum one-way ticket fares. The EAS has requirements such as service with not more than one connection, flights at reasonable times taking into account the needs of passengers with connections, and aircraft seat capacity (DoT, US, 2009).

\subsection{Aim and contributions}

The aim of the work presented in this paper is to develop a decision-support tool that can assist decision-makers in selecting an optimal network of subsidised routes. The paper has three major contributions. First, we present an estimation method for the subsidies of new routes. The estimation of route subsidies provides the data required by the model for assessing the selection of a new route to the network of subsidised routes. Secondly, we develop a budget-constrained optimisation model that can assess the current network and suggest an optimal network of subsidised routes. Thirdly, we use the model to evaluate the current subsidised routes and suggest a new set of routes that improve the accessibility.

\subsection{Related work}

Bråthen and Eriksen (2016) developed a method for assessing the level of service (LOS) on individual subsidised routes (PSO routes) in Norway through comparison of the socio-economic profitability of the subsidised routes with the best-alternative mode of transportation. A situation close to social optimum may be achieved by setting wise subsidy scheme targets. Pita, Antunes, Barnhart and de Menezes (2013) assessed the subsidised routes of Azores using an integrated flightscheduling and fleet-assignment model. The objective of their optimisation model was to minimise the incurred social cost of satisfying a given target demand which is set based on a subsidy scheme criteria.

Wittman (2014) assessed the accessibility of available air service in United States metropolitan regions by evaluating their quantity and quality. He used a connectivity index to generate accessibility scores at a regional level, and proposed a methodology to construct U.S. regional airport catchment areas using the United States Census Bureau Primary Statistical Areas (PSAs). Grubesic and Wei (2012) used data-envelopment analysis with a geographic information system to evaluate the efficiency of EAS at the community level. They also discussed policy implications and suggested strategies to improve the EAS program.

The debate of whether a subsidy scheme such as EAS is essential or superfluous has existed since the deregulation of airlines. Cunningham and Eckard (1987) used hypothesis testing to statistically analyse the impact of using subsidies to provide air services to small communities. They compared the airfares and service levels in certain cities for the period of 1978 to 1984, and concluded that the EAS subsidy program was superfluous because it had a negligible improvement in the level of air services in small communities. However, a later study by Özcan (2014) concluded that air passenger traffic is indeed essential as it contributes to the per-capita income of the communities. Özcan used a 2-stage least-squares model to evaluate the economic contribution of EAS flights on small and remote U.S. communities. These two conflicting results, in different time periods, further motivate the need for continuous evaluation of the benefits of subsidy schemes.

There has been work analysing the PSO system and EAS system from various angles, for example, Bråthen and Eriksen (2016); Pita et al. (2013); Wittman (2014); Grubesic and Wei (2012); 
Cunningham and Eckard (1987); Özcan (2014), and an extensive literature compilation by Williams and Bråthen (2012). However, the studies most similar and relevant for this paper are Flynn and Ratick (1988), Pita, Adler and Antunes (2014) and Matisziw, Lee and Grubesic (2012).

Flynn and Ratick (1988) used a maximal-covering model to evaluate options for the continuance of the EAS program. The model used two objectives to maximise coverage and minimise the systemwide cost. Using a case study of communities in North and South Dakota (USA), the model selected an optimal EAS network with its associated population coverage and minimum total cost. The model further identified the communities, which would continue to receive services, those which would have discontinued service, and those which needed more service and the type of service. Similar to our paper, the paper by Flynn and Ratick (1988) also maximised the population covered/accessibility with consideration of the cost.

Pita et al. (2014) presented a socially-oriented flight-scheduling and fleet-assignment (SFSFA) optimisation model. They called it 'an alternative style of cost-benefit analysis' with application to the Norwegian PSO network. The model sought for a PSO network that minimises the social cost while satisfying the demand. The social cost accounted for the operating costs and revenues of all stakeholders, i.e., passengers, airlines, airports and government. Our paper is similar to Pita et al. (2014) because it compares the existing network with the optimal network at a given budget.

Matisziw et al. (2012) used a bi-objective optimisation model to investigate alternative route configurations in the EAS that minimise the cost of communities accessing the hubs and maximise their accessibility to commercial air services within the whole air transportation system. The similarity to our paper is that they compared the observed/existing routes to the model optimal service structures. However the accessibility was approximated using the average outbound seats per-week for a given hub while the access cost was calculated as the demand-weighted cost.

This paper however differs from the previous work in three ways:

1. We evaluate the current Swedish network of subsidised routes and suggest an optimal network.

2. Instead of euclidean distance, we use ground transportation travel times so that the actual travel time to the destination is considered.

3. This paper presents a method of estimating the subsidies of new and future routes, based on subsidies for historical routes.

The rest of the paper is as follows. Section 2 presents the material and methods used; it includes a reformulation of our problem as a budgeted MaxCoverage problem and the corresponding Integer Programming (IP) model (Section 2.1 and Section 2.1.1, respectively), futher modifications made to the IP follow in Section 2.1.2, 2.1.3 and 2.1.4. A description of the case study and the data used, the models used to estimate the route subsidies and the number of revenue passengers can be found in Section 2.2, 2.4 and 2.3, respectively. The results and discussion in Section 3 are followed by the conclusion in Section 4.

\section{Material and methods}

\subsection{Reformulation as a budgeted MaxCoverage problem}

Here, the subsidised route-choice problem is formulated as a Budgeted Maximum Coverage problem. The input to the Maximum Coverage problem consists of a set $U$ (the universe), a collection $S$ of subsets of $U$ and a number $K$; the goal is to pick $K$ subsets from $S$ whose union contains as many elements of $U$ as possible (i.e., covers as much of the universe as possible - hence the name MaxCoverage). In the Budgeted MaxCoverage problem, each element $u \in U$ has a weight $w_{u}$, every subset $s \in S$ has a cost $c_{S}$ and instead of $K$, a budget $B$ is used to limit the number of selected subsets. The goal is to pick the subsets from $\mathcal{S}$, maximising the total weight of the elements in the union of the subsets such that their total cost does not exceed the budget $B$. It is convenient to represent an instance of the MaxCoverage problem with a $|U| \times|S|$ membership matrix $A$ where each 
row $u$ corresponds to an element of $U$ and each column $s$ represents a subset in $S$, and whose entry $A_{u s}=1$ or 0 depending on whether element $u \in s$ or not. Our subsidised route-choice problem entails the selection of routes to be subsidised such that people grouped into population centers can reach a given destination and the total amount of subsidies does not exceed a given budget. This problem reduces to the Budgeted MaxCoverage problem as follows: The universe is the set $P$ of the population centers; the weight $D_{p}$ of a center $p \in P$ is the number of people living in $p$. The potential subsidised routes $F$ define the subsets of $P$ : for each route $f \in F$, there is a subset $P_{f} \subseteq P$ of the population centers that are served by $f$ within the target travel time. That is, we create the $|P| \times|F|$ matrix $A$ whose entry $A_{p f}=1$ or 0 depending on whether $f$ provides a way to reach the destination from $p$ within a given time or not. The total cost of the selected routes should not exceed a budget $B$.

\subsubsection{IP for MaxCoverage}

The IP model is:

$$
\begin{array}{lll}
\max Z= & \sum_{p \in P} D_{p} y_{p} & \\
\text { s.t. } & \sum_{f \in F} c_{f} x_{f} \leq B & \\
& y_{p} \leq \sum_{f \in F} A_{p f} x_{f}, \quad \forall p \in P \\
& y_{p} \in\{0,1\}, \quad \forall p \in P \\
& x_{f} \in\{0,1\}, \quad \forall f \in F .
\end{array}
$$

where $B$ is the given budget and $x_{f}$ is the decision variable for whether the route $f$ is chosen $\left(x_{f}=1\right)$ or not $\left(x_{f}=0\right)$. The constraint $\sum_{f \in F} c_{f} x_{f} \leq B$ ensures that the cost of the selected routes does not exceed $B$. The constraints $y_{p} \leq \sum_{f \in F} A_{p f} x_{f}$ work as follows: if no subsidised route serves a population center $p$, then the $p$ th row in $A x$ is equal to 0 , so the $p$ th constraint in $y \leq A x$ reads $y_{p} \leq 0$, implying that $y_{p}=0$ and $D_{p}$ is not counted in the objective function; on the contrary, if at least one route serves $p$, then the $p$ th row in $A x$ is at least 1 , so $y_{p}$ may be equal to 1 (and it actually will be equal to 1 , since it can only be 0 or 1 ) and $D_{p}$ is counted towards the served population.

\subsubsection{Alternative modes of transportation}

Subsidised routes are not meant to compete with commercial flights or ground transportation. Population centres where people can travel to the destination by either a direct commercial flight or ground transportation should not be considered covered by any subsidised route. We therefore modify the constraints $y_{p} \leq \sum_{f \in F} A_{p f} x_{f}$ to:

$$
y_{p} \leq V_{p}+\sum_{f \in F} A_{p f} x_{f}, \quad \forall p \in P
$$

where $V_{p}$ is a parameter indicating whether a population centre can use either ground transportation or a commercial flight $\left(V_{p}=1\right)$ or not $\left(V_{p}=0\right)$.

\subsubsection{Route independence}

The routes are assumed to be independent, i.e., adding one specific subsidised route, will not affect the demand for other subsidised routes. While this is a reasonable assumption in most cases, it is not true for multiple routes from an airport to the same destination. For a set of airports $K$, a set of destinations $E$ and a set $O_{k}^{e}$ of flights $f$ that originate from each airport $k$ to destination $e \in E$, we ensure that each airport has at most one route to the same destination by adding a constraint:

$$
\sum_{f \in O_{k}^{e}} x_{f} \leq 1, \quad \forall k \in K, e \in E
$$




\subsubsection{Multiple accessibility targets}

In practice, it may be beneficial to assess the accessibility to more than one destination, which results into multiple accessibility targets. The consideration of more than one target results into multiobjective optimisation. The number of people $Z$ that can reach a destination can be maximised for multiple targets $t$. $Z^{t}$ indicates the maximum number of people who can reach the destination within a target $t$. Assuming $t=1,3$, where $Z^{1}$ is the accessibility to the capital within four hours and $Z^{3}$ is the accessibility to an international airport within four hours, weighted optimisation can be used to handle these multiple objectives. Weighted optimisation is applied when it is difficult to organise the targets based on priority (Marler and Arora, 2010). The objective functions are combined into one using weights $W_{t}$. In this case,

$$
W_{1} \cdot Z^{1}+W_{3} \cdot Z^{3}
$$

where it often can be beneficial to let $\sum_{t} W_{t}=1$. A high weight favors the objective, e.g. $W_{1}=0.3, W_{3}=0.7$ gives more incentive for the model to facilitate accessibility to an international airport.

\subsubsection{The complete IP model}

Combining the modifications for alternative modes of transportation, route independence and the possibility for multiple accessibility targets $(t \in T)$ with the IP for MaxCoverage in Section 2.1.1 gives the complete IP model:

$$
\begin{array}{lll}
\max Z= & \sum_{t \in T} \sum_{p \in P} W_{t} D_{p} y_{p}^{t} & \\
\text { s.t. } & \sum_{f \in F} c_{f} x_{f} \leq B & \\
& y_{p}^{t} \leq V_{p}^{t}+\sum_{f \in F} A_{p f}^{t} x_{f}, & \\
& \sum_{f \in O_{k}^{e}} x_{f} \leq 1, & \forall k \in P, t \in T \\
& y_{p}^{t} \in\{0,1\}, & \forall p \in P, t \in T \\
& x_{f} \in\{0,1\}, & \forall f \in F .
\end{array}
$$

where variable $y_{p}^{t}=1$ if population centre $p$ is covered with regards to Target $t$, parameter $A_{p f}^{t}=1$ or 0 depending on if route $f$ provides a way to reach the destination from $p$ with regard to Target $t$ or not, and the parameter $V_{p}^{t}=1$ if a population centre can use either ground transportation or a commercial flight with regard to Target $t$, otherwise it is zero. The rest of the parameters and variables are defined as in Section 2.1.1 and Section 2.1.3.

\subsection{The Swedish PSO scheme}

The model is used to evaluate the PSO scheme in Sweden as a case study. The calls to operate PSO routes are done by Trafikverket (the Swedish Transport Authority), which assesses the need for subsidised routes by municipalities based on the eight criteria presented in Table 1 (Trafikverket, 2013). We consider two of these, i.e., accessibility to Stockholm (the number of people that reaches the capital within a target time), and accessibility to an international airport. This generates the five targets used in this study (see Table 2).

Although considering only two of the eight criteria used by Trafikverket is simplistic, these are considered sufficient to illustrate the methodology developed in this paper. The two considered criteria can also be viewed as good representatives of the other six criteria. For example, the criteria for accessibility to Stockholm can be viewed to be representative to the accessibility from Stock- 
holm, since the model assumes return flights to each destination. Trafikverket evaluates the ability to travel to a destination in the morning, spend a sufficient amount of time there, and then return in the evening. The model does not enforce or restrict departure and arrival times, but this could easily be added as a requirement when implementing the suggested flights. In Table 1, Criteria 4-7 can also be considered to be partly covered by Criteria 1, since access to Stockholm also gives access to a major city, hospitals, universities.

Table 1

The eight criteria used by Trafikverket and their targets ( $a=$ Good and $b=$ Acceptable)

\begin{tabular}{|c|c|c|}
\hline Criteria & Description & Target \\
\hline 1. To Stockholm & $\begin{array}{l}\text { Reach central Stockholm } \\
\text { during the day }\end{array}$ & $\begin{array}{l}\text { a. Within } 4 \text { hours } \\
\text { b. Within } 5 \text { hours }\end{array}$ \\
\hline 2. From Stockholm & $\begin{array}{l}\text { Travel from Stockholm } \\
\text { to the municipality }\end{array}$ & $\begin{array}{l}\text { a. Within } 4 \text { hours } \\
\text { b. Within } 5 \text { hours }\end{array}$ \\
\hline $\begin{array}{l}\text { 3. International } \\
\text { travel }\end{array}$ & $\begin{array}{l}\text { Possibility of international air travel } \\
\text { by arriving at any of Stockholm-Arlanda, } \\
\text { Gothenburg-Landvetter, Copenhagen Kastrup, } \\
\text { Oslo Gardermoen and Trondheim Vaernes } \\
\text { airports on weekdays }\end{array}$ & Travel time is not specified \\
\hline 4. Major cities & $\begin{array}{l}\text { Accessibility to Stockholm, Gothenburg, } \\
\text { Malmö, Sundsvall, Umeå, Luleå, Linköping, } \\
\text { Copenhagen, Oslo or Trondheim }\end{array}$ & $\begin{array}{l}\text { a. Within } 5 \text { hours to at least } 1 \\
\text { city } \\
\text { b. Within } 5 \text { hours to at least } \\
\text { city }\end{array}$ \\
\hline $\begin{array}{l}\text { 5. Regional/University } \\
\text { hospital }\end{array}$ & $\begin{array}{l}\text { Accessibilty to a university or a regional } \\
\text { hospital in Umeå, Stockholm, Uppsala, } \\
\text { Örebro, Linköping, Gothenburg, Malmö } \\
\text { and Lund }\end{array}$ & $\begin{array}{l}\text { a. Within } 3 \text { hours } \\
\text { b. Within } 4 \text { hours }\end{array}$ \\
\hline $\begin{array}{l}\text { 6. University and } \\
\text { higher education }\end{array}$ & $\begin{array}{l}\text { Accessibility to higher education } \\
\text { in } 23 \text { municipalities }\end{array}$ & $\begin{array}{l}\text { a. Within } 5 \text { hours to at least } 10 \\
\text { target municipalities } \\
\text { b. Within } 5 \text { hours to at least } 5 \\
\text { target municipalities }\end{array}$ \\
\hline 7. Other major cities & $\begin{array}{l}\text { Accessibility to a municipality } \\
\text { with at least } 50,000 \text { inhabitants }\end{array}$ & $\begin{array}{l}\text { a. Within } 3 \text { hours to at least } 3 \\
\text { target municipalities } \\
\text { b. Within } 4 \text { hours to at least } 2 \\
\text { target municipalities }\end{array}$ \\
\hline 8. Tourism & $\begin{array}{l}\text { The possibility for the rest of } \\
\text { the country to reach an essential } \\
\text { population center in the municipality }\end{array}$ & $\begin{array}{l}\text { a. } 50 \% \text { of the Swedish population } \\
\text { reaches the population center } \\
\text { within } 5 \text { hours } \\
\text { b. } 50 \% \text { of the Swedish population } \\
\text { reaches the population center } \\
\text { within } 7 \text { hours }\end{array}$ \\
\hline
\end{tabular}

Source: Trafikverket, 2013

Table 2

The criteria and targets used in this study

\begin{tabular}{lc}
\hline Accessibility criterion & \multicolumn{1}{c}{ Target } \\
\hline To Stockholm & 1. Less than 4 hours \\
\cline { 2 - 2 } & 2. Less than 5 hours \\
\hline To an international airport & 3. Less than 4 hours \\
\hline $\begin{array}{l}\text { To Stockholm and } \\
\text { an international airport }\end{array}$ & $\begin{array}{l}\text { 4. Target } 4 \text { simultaneously combines } \\
\text { Target } 1 \text { and Target } 3 \text { using weights }\end{array}$ \\
\cline { 2 - 2 } & $\begin{array}{l}\text { 5. Target } 5 \text { simultaneously combines } \\
\text { Target } 1, \text { Target } 2 \text { and Target } 3 \\
\text { using weights }\end{array}$ \\
\hline $\begin{array}{l}\text { a The international airports considered by Trafikverket are Stockholm- } \\
\text { Arlanda, Gothenburg-Landvetter, Copenhagen Kastrup, Oslo Gardermoen } \\
\text { and Trondheim Vaernes. }\end{array}$
\end{tabular}




\subsubsection{Population, travel times and routes}

The population is aggregated into population centres and we assume that people in a given population centre make the same travel choice. Statistics Sweden (2017) was the source of data on the Swedish geographical boundaries that were used in the study. This data included variables such as population-centre (known as "tätort") name, location coordinates and the population. 1949 population centres were considered because they have ground access to at least one airport.

We categorise the journey into three phases: (1) Passengers travel from their population centres to the airport by ground transportation such as private cars, taxis or public transportation; (2) Flight from the departure airport to an arrival airport closest to the final destination. This phase includes waiting and processing times at both airports; (3) The final phase is the possible use of ground transportation from the arrival airport to the final destination, unless the arrival airport is the final destination. The total travel time is the sum of the two ground travel times, the flight time, and the waiting and processing times.

The ground travel time from the population centres to the destination (i.e., centre of the capital or airports) for both private cars and public transportation is obtained from the TravelTime platform (2019). For the case of public transportation, the mimimum of the travel times for journeys starting from 05:00 am to 08:00 pm, with one hour increment, is used.

The data on airports were obtained from Openflights.org (2018). Only 44 instrument airports were included because scheduled and charter traffic are only allowed on such (Transportstyrelsen, 2018). All the flight times were calculated based on a Saab 340 aircraft because it is the most common aircraft used along subsidised routes in Sweden. The $R$ software was used to web scrap the The Great Circle Mapper (2019) for flight times of various routes.

A subsidised route has the possibility to affect travel options in the model (Figure 1). For some population centre, it might be possible to travel by train, car, bus or plane; but for evaluation purposes, the mode offering the shortest travel time is of interest. For example, consider one population centre where the quickest way to reach the capital currently takes five hours, by ground transportation (bus or train). Adding a subsidised route from a nearby Airport A to the capital may make it possible to reduce the travel time to three hours, and thus achieve the defined target for that population centre. If another subsidised flight is considered through nearby Airport B (in Figure 1), the population center will utilise this new option if it improves the accessibility by satisfying a given target time.

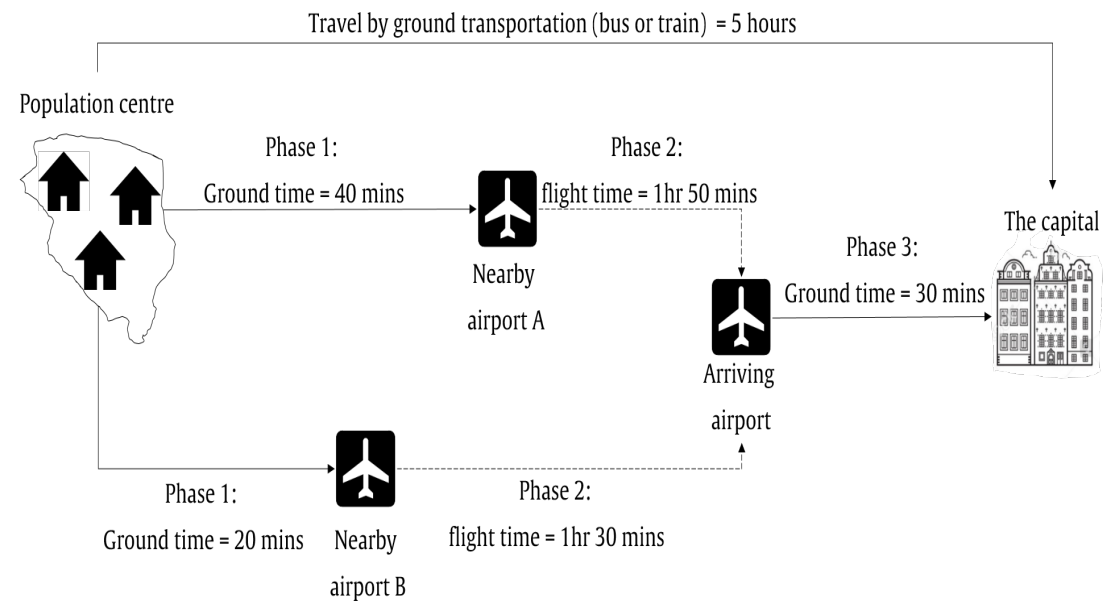

Figure 1: Effect of subsidised routes on travel options

\subsubsection{Current and new routes}

There are currently seven PSO routes (Figure 2). In this study we consider five of these as open for reconstruction, i.e. the ones with Stockholm-Arlanda airport as their final destination. The route Åre 
Östersund-Umeå facilitates access to a university hospital (in Umeå), an accessibility criterion that we do not consider here. Passengers along the Pajala-Luleå route can transfer to a commercial route from Luleå to Stockholm-Arlanda airport, thus facilitating access to Stockholm for people around Pajala. While we consider the accessibility to Stockholm, we do not consider the possibility to connect PSO routes to commercial routes. Therefore, from a modelling perspective the Pajala-Luleå-StockholmArlanda possibility is treated as a commercial route, and the system that makes up our study context consists of the five PSO routes indicated with solid lines in Figure 2. In this base case, there are eight airports as origins for the current PSO routes to Stockholm-Arlanda airport; this consists of two non-stop and three one-stop PSO route combinations. Furthermore, the current airport network has 26 additional airports that can accommodate PSO routes, giving a total of 1225 possible PSO routes to choose from. The candidate PSO routes used in this paper included both non-stop and one-stop routes to Stockholm-Arlanda airport. The current commercial flights were obtained from Google Flights (2019) whereas the possible PSO routes and current PSO routes were retrieved from Openflights.org (2018) and Trafikverket (2017), respectively.

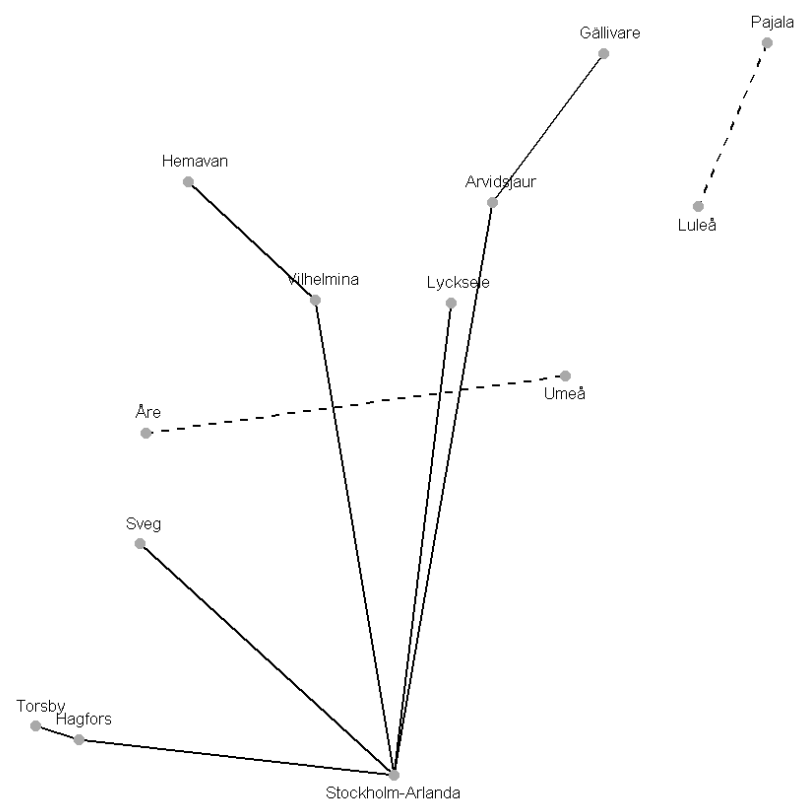

Figure 2: The current Swedish PSO routes

\subsection{Estimating the number of revenue passengers $(P a x)$}

The factors that affect the number of revenue passengers in air transportation include the population, total trip time, ticket price, the supply by the air carriers such as number of flights offered, the trip purpose and competition from other modes of transportation (Belobaba, Odoni and Barnhart, 2015). These factors are typically used as independent variables in regression models with revenue as the dependent variable. For example, Kopsch (2012) used variables such as population, ticket prices, purpose of travel and prices for using rail transportation in a log-linear regression demand model for the domestic air travel in Sweden. Other work such as Fridström and Thune-Larsen (1989), Brown and Watkins (1968) and Battersby and Oczkowski (2001) have used regression models and combinations of these variables.

Here, we define the route subsidy as the difference between the route Operation cost and Revenue. The Revenue depends on the number of revenue passengers (Pax), which is not available for possible new routes and hence requires to be estimated. The $\operatorname{Pax}_{i j}$ between airports $i$ and $j$ is estimated by 
the log-linear model:

$$
\log \left(\operatorname{Pax}_{i j}\right)=\delta_{0}+\delta_{1} \cdot \log \left(C_{i j}\right)+\delta_{2} \cdot T_{i j}^{\text {diff }}+\delta_{3} \cdot \text { flights }_{i j},
$$

where $C_{i j}$ is the square root of the product of the population $C_{i}$ and $C_{j}$ that is within 1 hour driving time of the two airports. $T_{i j}^{d i f f}$ is the difference between the flight time and ground travel time from the origin to the final destination; the larger this difference, the harder it is to travel by ground transportation and the higher the number of revenue passengers for air transportation. flights $s_{i j}$ is the number of annual flights for a given route.

The parameters of the Pax model are estimated by the Ordinary Least Squares (OLS) method using the historical annual Pax and annual flight frequencies from the period of 2015 to 2017, which was obtained from the Trafikverket report (Trafikverket, 2017). The estimated Pax model is $\log \left(\operatorname{Pax}_{i j}\right)=0.095 \cdot \log \left(C_{i j}\right)+0.317 \cdot T_{i j}^{\text {diff }}+0.005 \cdot$ flights $_{i j}$. For our case, including the constant $\delta_{0}$ gave systematically high $P a x$ estimates and thus it was excluded from the final model. The final model gives predictions that are correct on average because they are neither systematically high nor low as in the validation plots in Figure 3. Figure 3a shows how the Pax model residuals on the $\mathrm{y}$-axis vary with the estimated Pax on the $\mathrm{x}$-axis while Figure $3 \mathrm{~b}$ presents the comparison of the actual subsidies on the y-axis and the estimated Pax for the year 2016.

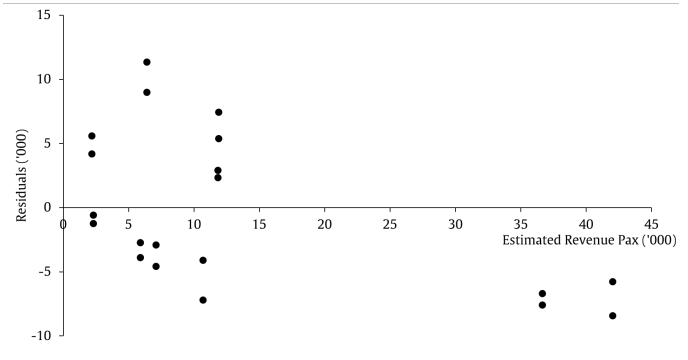

(a) Residuals versus estimated $P a x$

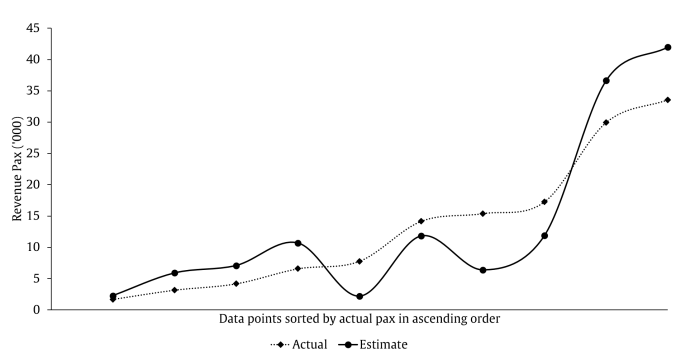

(b) Actual and estimated Pax for 2016

Figure 3: Validation plots for the Pax model

The Pax data for the PSO routes obtained from Trafikverket is presented as origin-destination, hence it is hard to identify the Pax for one-stop route configurations, which is how some routes are operated. We use the model to estimate the Pax for a given origin-destination, but explicitly take into account the additional flight time in a one-stop route using $T_{i j}^{d i f f}$. Thus, the estimated Pax from e.g. Torsby to Stockholm, going through Hagfors, will be lower than for a direct route between Torsby and Stockholm Arlanda. The total Pax for one-stop routes is calculated as the sum of two the separate $P a x$ values for each origin. For example, the $P a x$ for Torsby-Hagfors-Stockholm Arlanda is the sum of the Pax for Hagfors-Stockholm Arlanda and the Pax from Torsby to Stockholm Arlanda through Hagfors.

\subsection{Estimating the route subsidies}

We assume that the route Operation cost varies based on the travelled distance measured in kilometres $(\mathrm{km})$. We estimate the Operation cost using a log-log linear equation $\log ($ Operation cost $)=$ $\gamma_{0}+\gamma_{1} \cdot \log ($ distance $)$ where $\gamma_{0}$ and $\gamma_{1}$ are parameters to be estimated by OLS method.

The Revenue is calculated as the product of Pax and the Average price. Similar to Bubalo (2012) and Lian, Thune-Larsen and Draagen (2010), we estimate the average price as $75 \%$ of the Maximum price set for a given route by Trafikverket during the tendering process, i.e., Average price = $0.750 *$ Maximum price. The Maximum price is estimated by a linear relationship Maximum price $=$ $\pi_{0}+\pi_{1} \cdot G C D$ where $\pi_{0}$ and $\pi_{1}$ are parameters to be estimated, and the GCD is the great-circle distance from the origin to the destination (Bubalo, 2012; Lian et al., 2010). 
The route subsidy is estimated by the log-log equation:

$$
\log (\operatorname{subsidy})=\beta_{0}+\beta_{1} \cdot \log (\text { Revenue })+\beta_{2} \cdot \log (\text { Operation cost })
$$

with $\beta_{0}, \beta_{1}, \beta_{2}$ as parameters to be estimated by OLS method.

To estimate the parameters for the Operation cost, Maximum price and subsidy models, historical route data from the Trafikverket report (Trafikverket, 2017), containing the number of passengers and annual subsidies (in Swedish Krona-SEK) for the period from 2016 to 2017 was used. The equations $\log ($ Operation cost $)=11.439+0.886 \cdot \log ($ distance $)$ and Maximum price $=$ $630+0.900 \cdot G C D$ were estimated and used. Both of these equations give reasonable estimates compared to the Operation cost and Maximum price of the available data for current routes. The estimated subsidy model is:

$$
\log (\operatorname{subsidy})=2.285-0.280 \cdot \log (\text { Revenue })+1.096 \cdot \log (\text { Operation cost })
$$

and with an adjusted R-square of $90.6 \%$, the model gives predictions that are correct on average because they are neither systematically high nor low (Figure 4). Figure 4a shows how the model residuals on the $y$-axis vary with the estimated subsidies on the $\mathrm{x}$-axis while Figure $4 \mathrm{~b}$ presents the comparison of the actual subsidies on the y-axis and the estimated subsidies (sorted in ascending order) for the year 2016 .

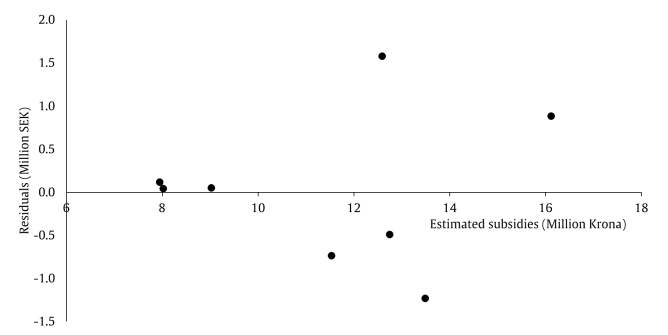

(a) Residuals versus estimated subsidies

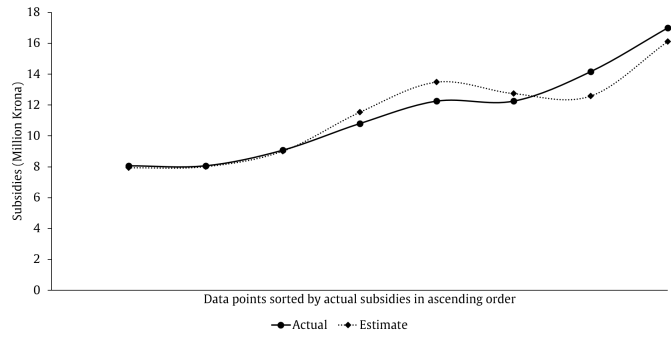

(b) Actual and estimated subsidies for 2016

Figure 4: Validation plots for the subsidy model

\section{Results and discussion}

The model indicates that most of the population do not need subsidised (PSO) routes to reach the target destination. They can either travel by ground transportation to the final destination or use a combination of ground transportation to the airport, a commercial flight to the final airport and possibly ground transportation from the airport to the final destination. Subsidised routes aim to improve accessibility of small communities to certain destinations. Therefore, the number of people with improved accessibility is used to assess the current subsidised routes (known as the base case) and the optimal network of subsidised routes suggested by the model. This analysis is made for all the targets in Table 2, and constitutes the first scenario.

Stockholm's second largest airport, Stockholm-Bromma is a hot topic in Sweden because of the political pressure to close it by 2022, while a possibly more realistic alternative that is being discussed is to stop the operations after 2038, when a new runway has been built at Stockholm-Arlanda airport. The closure of Stockholm-Bromma airport might lead to a reduction in the number of commercial flights that are used to access Stockholm, for example the current commercial routes from the airports Halmstad, Jönköping, Kristianstad, Trollhättan and Växjö-Kronoberg to Stockholm-Bromma airport. This is an example of a location decision to be made, i.e., whether to continue operations at Stockholm Bromma airport or to close it. Therefore, the second scenario, about the closure of 
Stockholm-Bromma airport is used to illustrate how the model also can be used to make airport location decisions.

\subsection{Scenario 1: The current airport network}

\subsubsection{Accessibility without $P S O$ routes}

Considering the current airport network, our model shows that $98.69 \%$ and $99.74 \%$ of the population already can reach Stockholm within four and five hours, respectively, either by ground transportation or by commercial flight. This implies that PSO route(s) can be used to improve the accessibility for the remaining $1.31 \%$ and $0.26 \%$ of the population, i.e., 123,079 and 24,019 people, respectively. Additionally, $98.42 \%$ of the population can already access an international airport within four hours, making it possible to improve the situation for $1.58 \%$ (i.e., 148,337) of the population.

\subsubsection{Accessibility with the current PSO routes}

Here, we assess the extent to which the current PSO routes to Stockholm-Arlanda airport improves the accessibility for the population that cannot reach the target destination either by ground transportation or by a commercial flight.

The introduction of the current five PSO routes improves the accessibility for an additional 97,225 people to reach Stockholm within four hours, and 16,620 people to reach Stockholm within five hours. In the case of accessibility to an international airport within four hours, the current PSO routes improve the accessibility for 97,060 people.

\subsubsection{Accessibility with optimal PSO routes}

The current five PSO routes have an estimated subsidisation cost of SEK 56.4 million. To compare these current PSO routes with the optimal solutions from the model, we use a budget constraint of SEK 50 million.

Targets 1 and 2: These targets aim to individually maximise the number of people that can reach Stockholm city within four hours, and within five hours, respectively. Each target gives a single optimisation objective, i.e., to maximise the number of people covered within the target time. Figure 5 shows the number of people with increased accessibility (y-axis) for Target 1 and 2 for various subsidy budgets (x-axis). At a subsidy budget of SEK 50 million, the corresponding optimal sets of routes for both targets are shown in Figure 6.

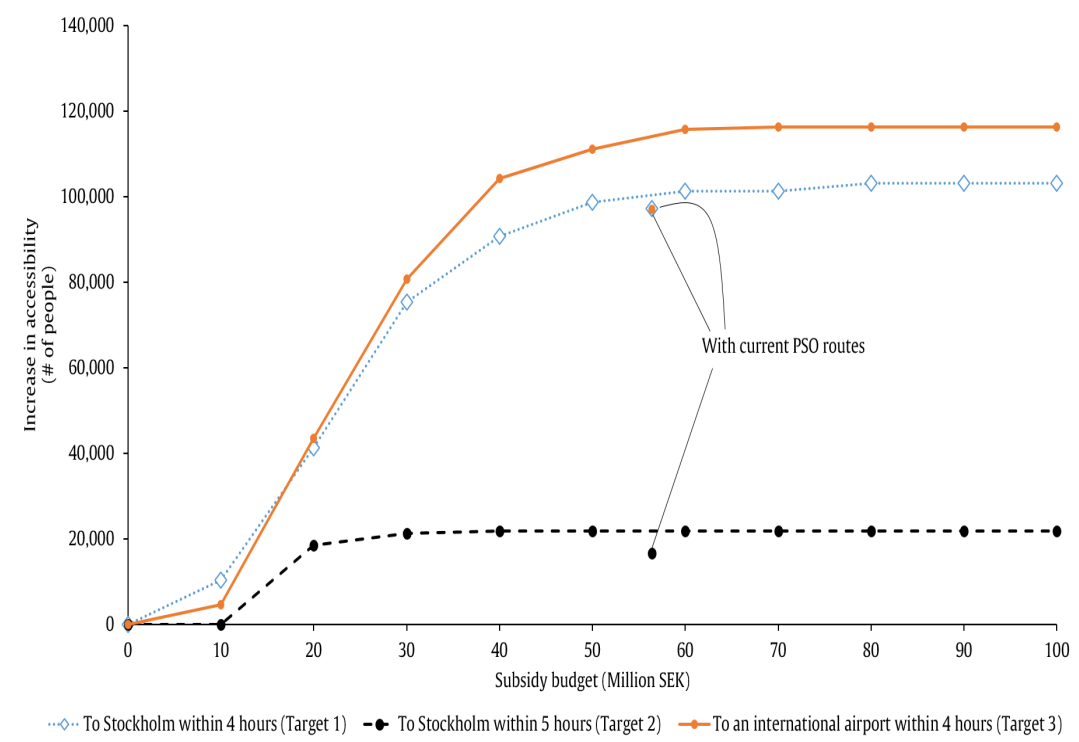

Figure 5: Improvement in accessibility of Targets 1, 2 and 3 for each PSO budget with the current airport network 
When considering Target 1, the current PSO route from Lycksele to Stockholm-Arlanda is replaced with a new one-stop route Lycksele-Kramfors-Stockholm Arlanda (Figure 6a). At a lower subsidisation of SEK 45.8 million, the selected optimal PSO routes increase the number of people served with respect to Target 1 from 97,225 in the base case to 98,672. With respect to Target 2, replacing the current PSO routes with three one-stop routes (Figure 6b) would provide accessibility to an additional 21,835 people, at a cost of SEK 39.5 million, an increase with $31 \%$ compared to the base case. For Target 2, the current direct route from Lycksele (see Figure 2), is replaced with a route

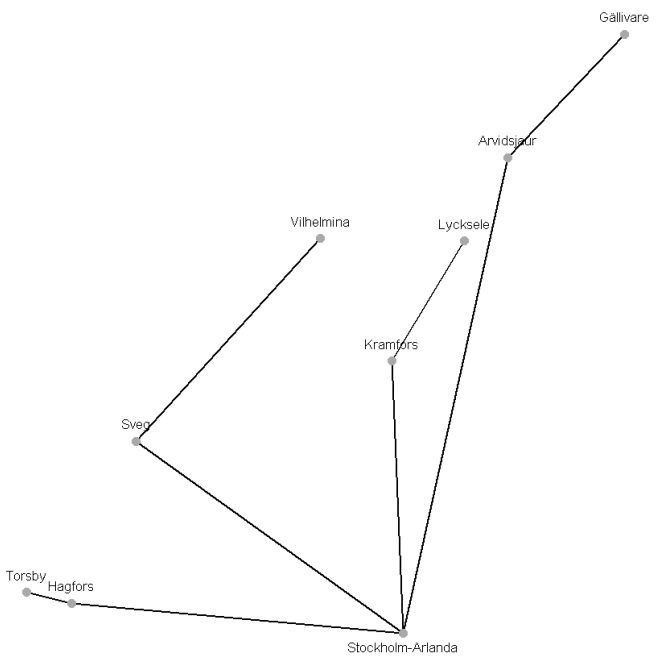

(a) Within four hours

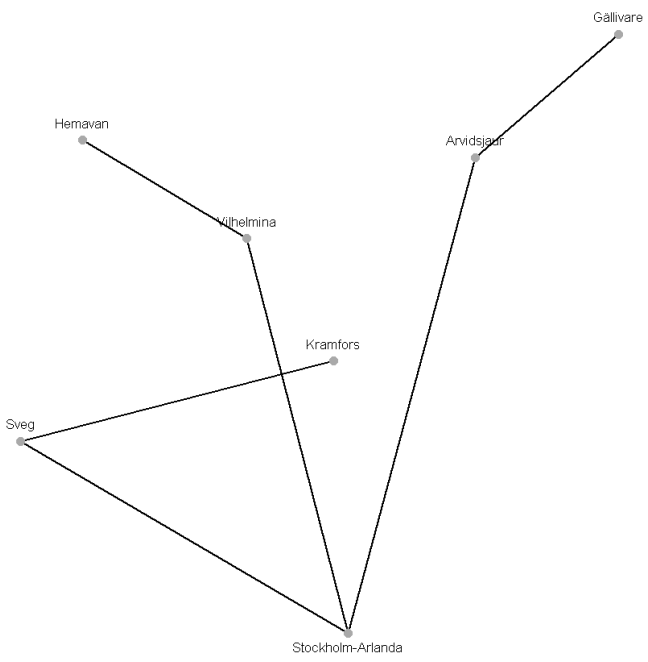

(b) Within five hours

Figure 6: The optimal routes for accessibility to Stockholm with the current airport network at a budget of SEK 50 million

Kramfors-Sveg-Stockholm Arlanda (see Figure 6b). This may not look like a good choice, because of the extra travel time for passengers starting in Kramfors, however:

- The five-hour target allows for people in Lycksele to access Stockholm by other alternatives. For example, they can drive for two hours to Vilhelmina airport and use a subsidised route or drive for two hours to Umeå airport and use a commercial flight to Stockholm Arlanda.

- While a more intuitive alternative might be to select the routes Hemavan-Sveg-Stockholm Arlanda and Vilhelmina-Kramfors-Stockholm Arlanda (instead of Hemavan-Vilhelmina-Stockholm Arlanda and Kramfors-Sveg-Stockholm Arlanda), this would not give any additional accessibility with respect to Target 2 . Furthermore, the total route distance would be longer, giving a higher operational cost, and thus more subsidies are required. Never-the-less, from a modelling perspective, this alternative set of routes also provide an optimal solution, since the total subsidy is is still under the budget of SEK 50 million.

- Even though the effect that additional travel time has on the demand is captured in the parameter $T_{i j}^{d i f f}$, the fact that some passengers might be more reluctant to use a flight where the first stop is an obvious detour, is not taken into account. Thus, to avoid such solutions, it is beneficial to take several criteria into account simultaneously, like in Target 4 and 5.

Target 3: Here, the model switches focus from trying to improve the accessibility to Stockholm city, and instead tries to ensure that as many people as possible can reach an international airport within four hours. From a modelling perspective, this means focusing on multiple destinations (i.e., five airports), instead of just one. Having a budget of SEK 50 million improves the accessibility to an international airport for 111,097 people (Figure 5). The cost for the four PSO routes (Figure 7) in the solution is 48.6 million, which is a significant reduction compared to the base case (with five 
routes that cost SEK 56.4 million). The optimal routes with respect to Target 3 and Target 1 are similar with an exception of the Torsby-Hagfors-Stockholm Arlanda route, which is not selected for the accessibility to an international airport. However, this route is selected when the subsidy budget is increased to SEK 60 million.

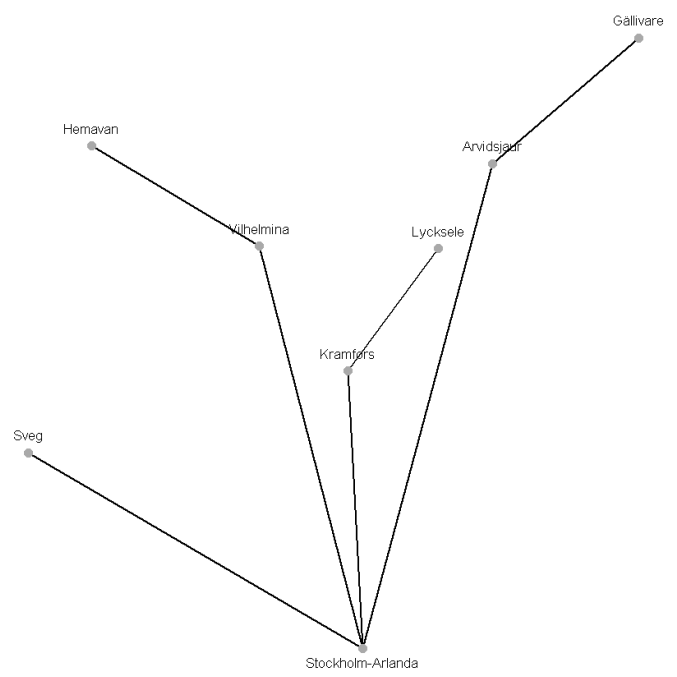

Figure 7: The optimal routes for accessibility to an international airport with the current airport network at a budget of SEK 50 million

Target 4: Target 4 considers both Target 1 and Target 3 and simultaneously maximises the number of people that can: (1) access Stockholm within four hours, and (2) access an international airport within four hours. Thus it is a combination of two different criteria where we weight the two resulting objectives. To illustrate this, we begin by using a value of $W_{1}=W_{3}=0.5$ and various budget values (see Figure 8). At a budget of SEK 50 million, 98,672 and 108,891 people have improved accessibility to Stockholm and to an international airport within four hours, respectively. Compared to when Target 1 and 3 are considered individually, using weights results into the same number of people with improved accessibility to Stockholm within four hours but less people with improved accessibility to an international airport within four hours. The optimal routes are presented in Figure $9 \mathrm{a}$ and are the same as the routes selected when Target 1 is individually considered.

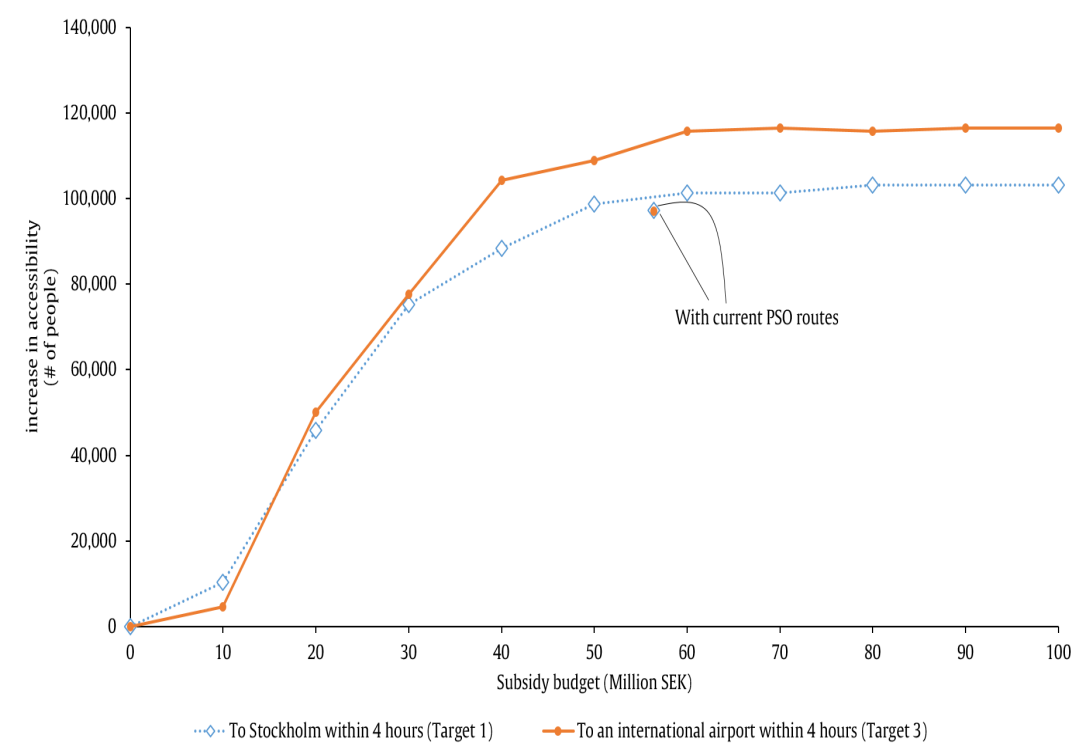

Figure 8: Improvement in accessibility for Targets 4 for each PSO budget value with the current airport network 


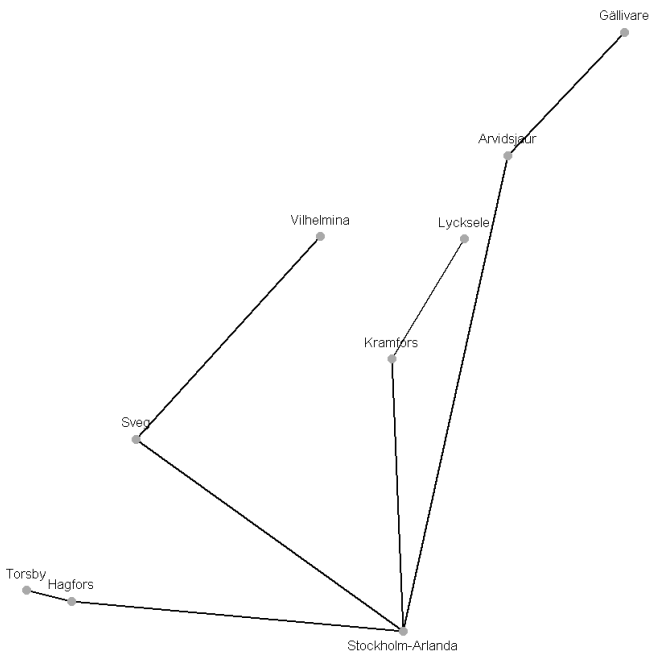

(a) Using $W_{1}=0.5$ at a budget of SEK 50 Million

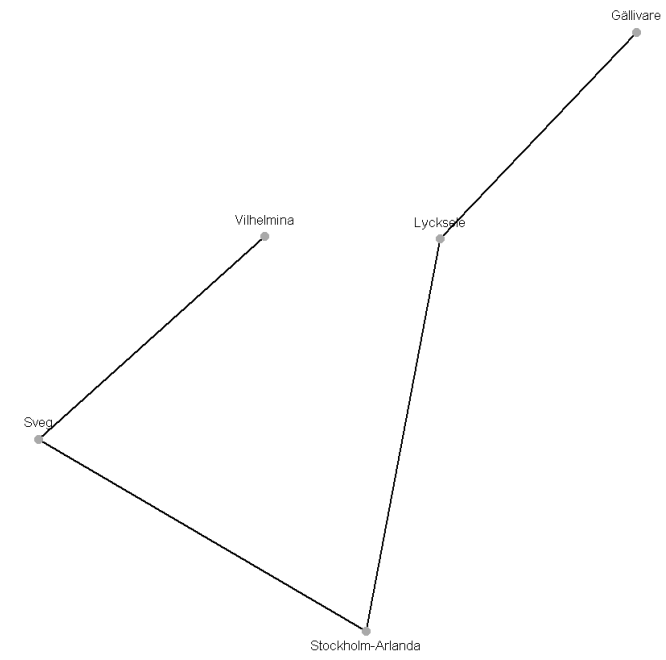

(b) Using $W_{1}=0.5$ at a budget of SEK 30 Million

Figure 9: The optimal route network for simultaneously considering both the accessibility to Stockholm and to an international airport within four hours using the current airport network

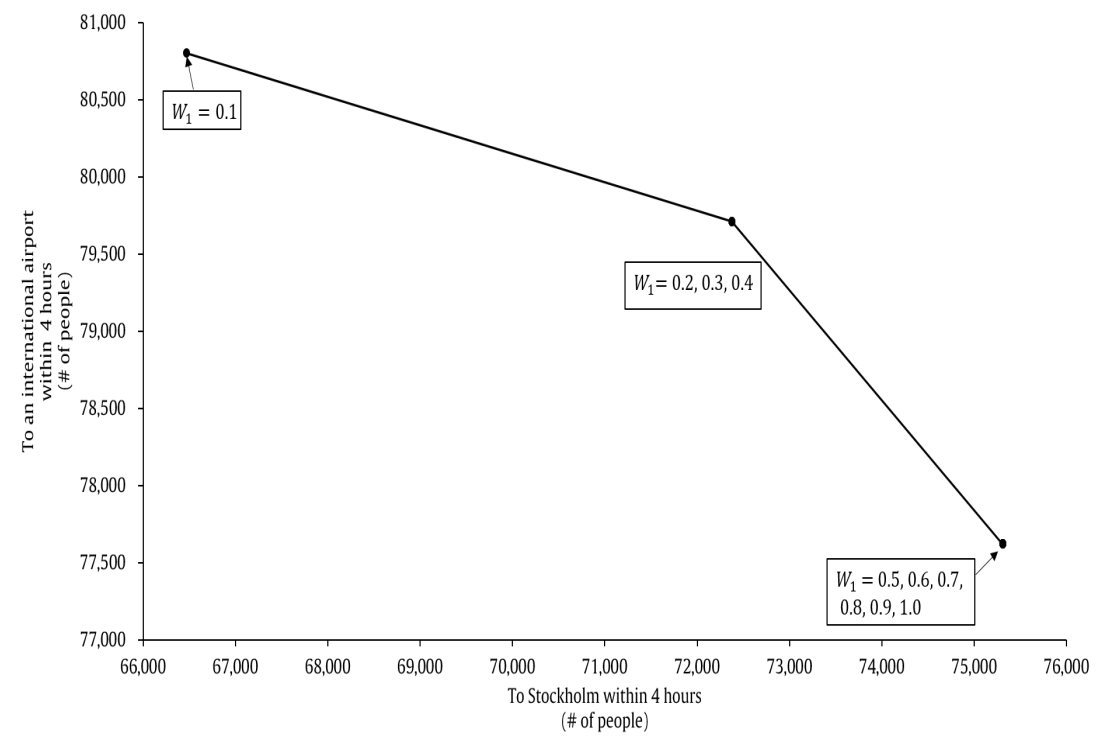

Figure 10: Pareto frontier for simultaneously considering both the accessibility to Stockholm and to an international airport within four hours using the current airport network, at a budget of SEK 30 Million and different values of $W_{1}$

At a subsidy budget of SEK 50 million, the number of people with increased accessibility to both Stockholm and an international airport within four hours is close to the maximum possible increase in accessibility. In this case, varying the weights does not result into any trade-off between Target 1 and Target 3. We therefore use a lower subsidy budget of SEK 30 million to illustrate this tradeoff. Figure 10 shows the pareto frontier illustrating the dominant solutions when a subsidy budget of SEK 30 million is used with various values of $W_{1}$, where $W_{1}+W_{3}=1$. Choosing the value of $W_{1}=W_{3}=0.5$ gives an optimal set of routes in Figure $9 \mathrm{~b}$ where the one-stop route from Gällivare goes through Lycksele instead of Arvidsjaur, compared to when a higher subsidy budget of SEK 50 million is used (see Figure 9a).

Target 5: Here, Target 1, 2 and 3 are simultaneously maximised using the weights $0.156,0.705$, and 0.139 , respectively. We choose the weights based on the individual optimal solutions for each Target and a budget constraint of 50 million, i.e. $Z^{1 *}, Z^{2 *}$ and $Z^{3 *}$. The weights are set so that $W_{1} Z^{1 *}=W_{2} Z^{2 *}=W_{3} Z^{3 *}$ and $W_{1}+W_{2}+W_{3}=1$, i.e., the individual optimal increase in ac- 
cessibility for the three targets contribute equally to the single target. With these weights, Figure 11 shows the number of people with improved accessibility to Stockholm within four hours, to Stockholm within five hours and to an international airport within four hours. Having a subsidy budget of SEK 50 million results into an improved accessibility for 98,672, 19,724 and 108,871 people, with respect to Target 1, 2 and 3, respectively. Compared to when the targets are considered individually, using weights results into the same number of people with improved accessibility to Stockholm within four hours but a less number of people with improved accessibility to both Stockholm within five hours and to an international airport within four hours. The optimal routes obtained by simultaneously considering all the three targets are the same as in Figure 6a when the accessibility to Stockholm within four hours is individually considered. Increasing the budget to 60 million, Hemavan airport is added to the network.

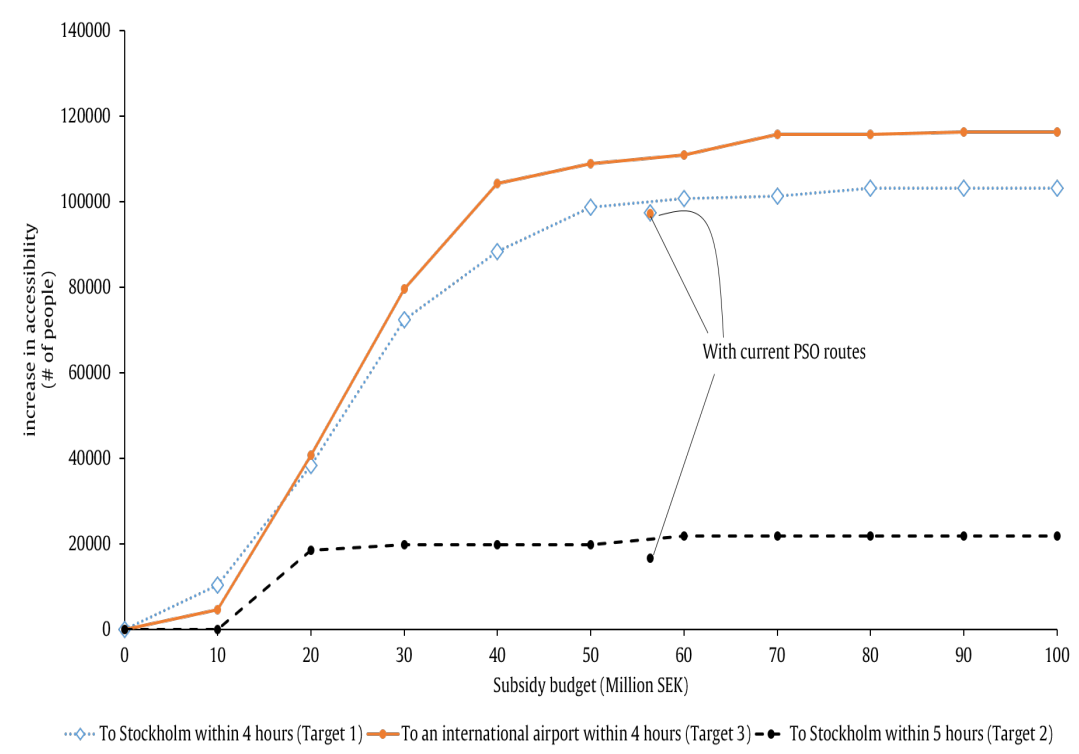

Figure 11: Improvement in accessibility for Target 5 for each PSO budget value with the current airport network

\subsection{Scenario 2: The closure of Stockholm-Bromma airport}

\subsubsection{Accessibility without $\mathrm{PSO}$ routes}

In the scenario with the closure of Stockholm-Bromma airport, $98.55 \%$ and $99.74 \%$ of the population can reach Stockholm within four and five hours, respectively, either by ground transportation or by commercial flight. Therefore PSO route(s) can be used to improve the accessibility for the remaining $1.45 \%$ and $0.26 \%$ of the population, i.e., 135,633 and 24,019 people, respectively. The closure of Stockholm-Bromma airport would result into an additional 12,554 people not being able to reach Stockholm city within four hours compared with when the airport continues operating.

\subsubsection{Accessibility with the current PSO routes}

With the closure of Stockholm-Bromma airport, the current five PSO routes would improve the accessibility to Stockholm within four hours and within five hours for the same number of people as when Stockholm-Bromma airport continues operations. However, 12,554 people lose their four hour accessibility to Stockholm due to the closure of Stockholm-Bromma airport. This suggests that the current PSO routes would not improve their accessibility unless adjusted to do so, for example, by having a new PSO route to Stockholm-Arlanda airport as a substitute for a no longer existing commercial flight to Stockholm-Bromma airport. 


\subsubsection{Accessibility with optimal PSO routes}

Target 1 and 2: Assuming Stockholm-Bromma airport is closed, the selected set of routes given the considered criteria and assumptions, gives the results shown in Figure 12. Replacing the five current PSO routes with four new routes but at a cheaper cost of SEK 49.7 million, increase the number of people served with respect to Target 1 to 113,875. The route Trollhättan-Hagfors-Stockholm Arlanda becomes a substitute to a commercial route from Trollhättan airport to Stockholm Bromma airport. For Target 2, the solution does not change compared to when Stockholm-Bromma is open (see Figure 13).

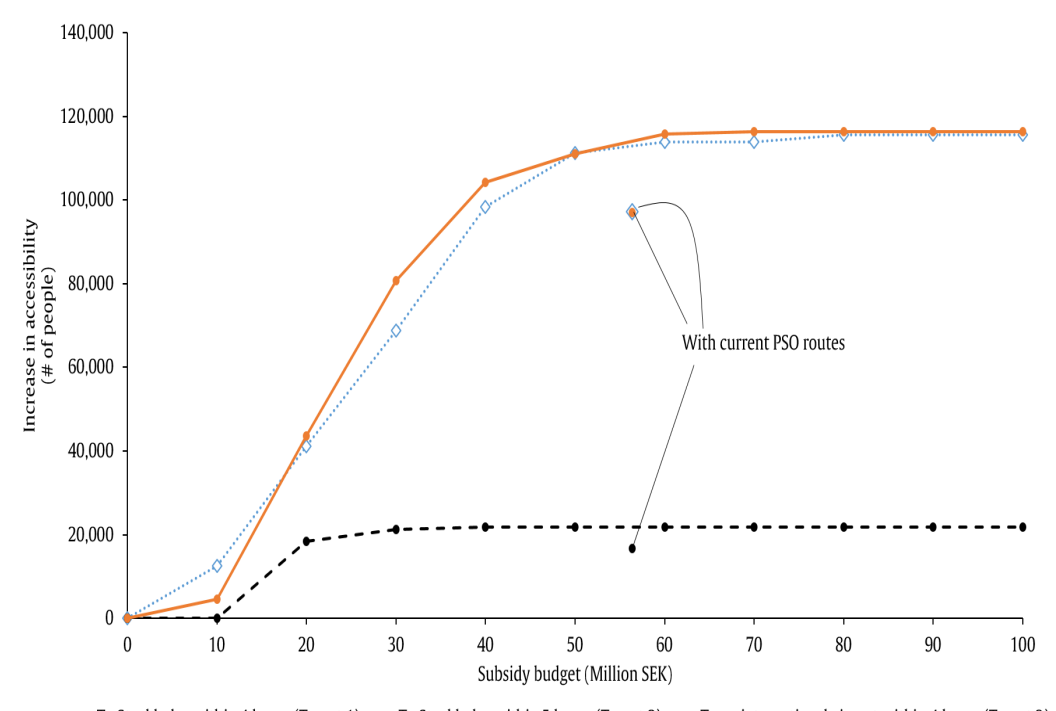

Figure 12: Improvement in accessibility of Targets 1, 2 and 3 for each PSO budget value with StockholmBromma airport closed

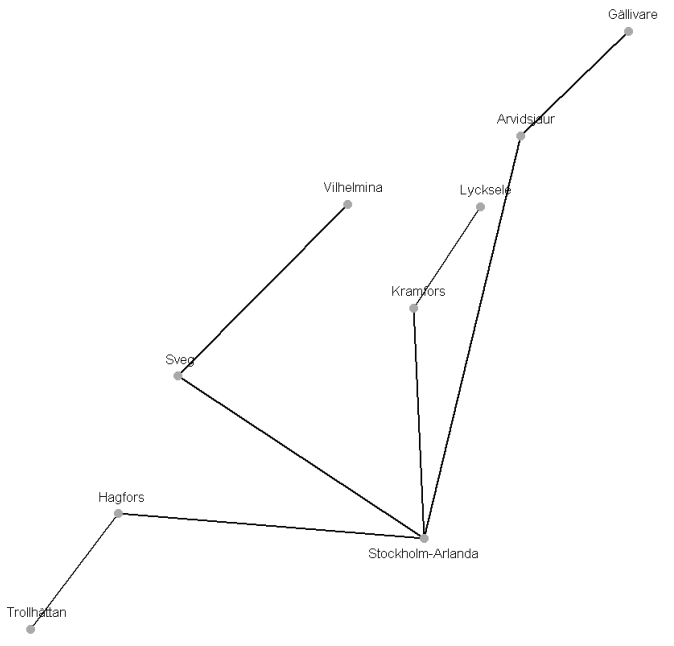

(a) Within four hours

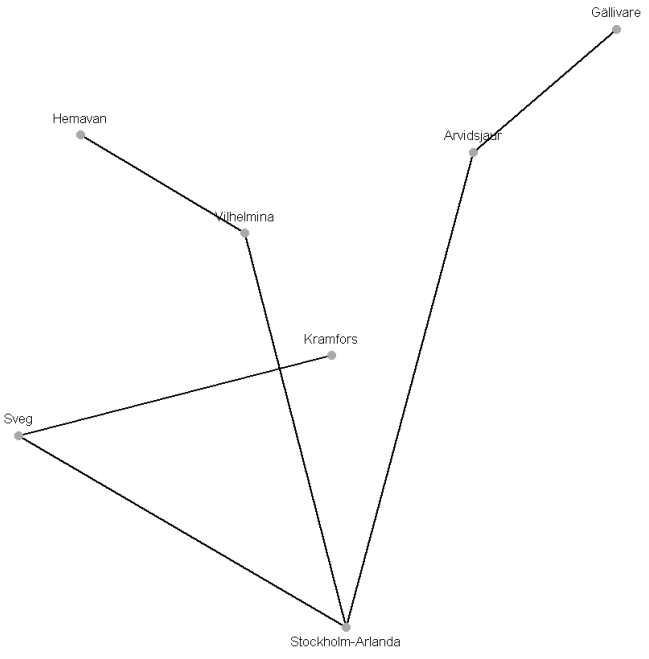

(b) Within five hours

Figure 13: The optimal routes for accessibility to Stockholm with Stockholm-Bromma airport closed at a budget of SEK 50 million

Target 3: If Stockholm-Bromma airport is closed, the number of people with improved accessibility to an international airport within four hours would not be affected compared to if it is open. For example, having a budget of SEK 50 million would still improve the accessibility to an international airport for 111,097 people (Figure 12), which is the same number of people as if Stockholm Bromma airport continues to operate (see Figure 5). 
Target 5: As in Section 3.1.3, we simultaneously maximise for Target 1, 2 and 3 using the weights $0.141,0.718$ and 0.141 , respectively (based on the individual optimal solutions). With these weights, Figure 14 shows the number of people with improved accessibility to Stockholm within four hours, to Stockholm within five hours and to an international airport within four hours in the scenario if Stockholm-Bromma airport is closed. Having a subsidy budget of SEK 50 million results into an improved accessibility for 111,226, 19,724 and 108,871 people, with respect to Target 1, 2 and 3 .

Compared to when Targets 1, 2 and 3 are considered individually, using weights results into the same number of people with improved accessibility to Stockholm within four hours but less number of people with improved accessibility to both Stockholm within five hours and to an international airport within four hours. The optimal routes obtained by simultaneously considering all the three targets are the same as in Figure 13a when the accessibility to Stockholm within four hours is individually considered. It is interesting to note that for a budget of 60 million, the number of people served with respect to Target 1 , actually drops, compared to the 50 million budget. What happens is that Hemavan airport is added to the network, while Trollhättan airport is dropped. Thus the number of people served with respect to Target 2 and 3 increases, thanks to the Hemavan route, while the number of people that can access Stockholm city within four hours decreases when the Trollhättan route disappears.

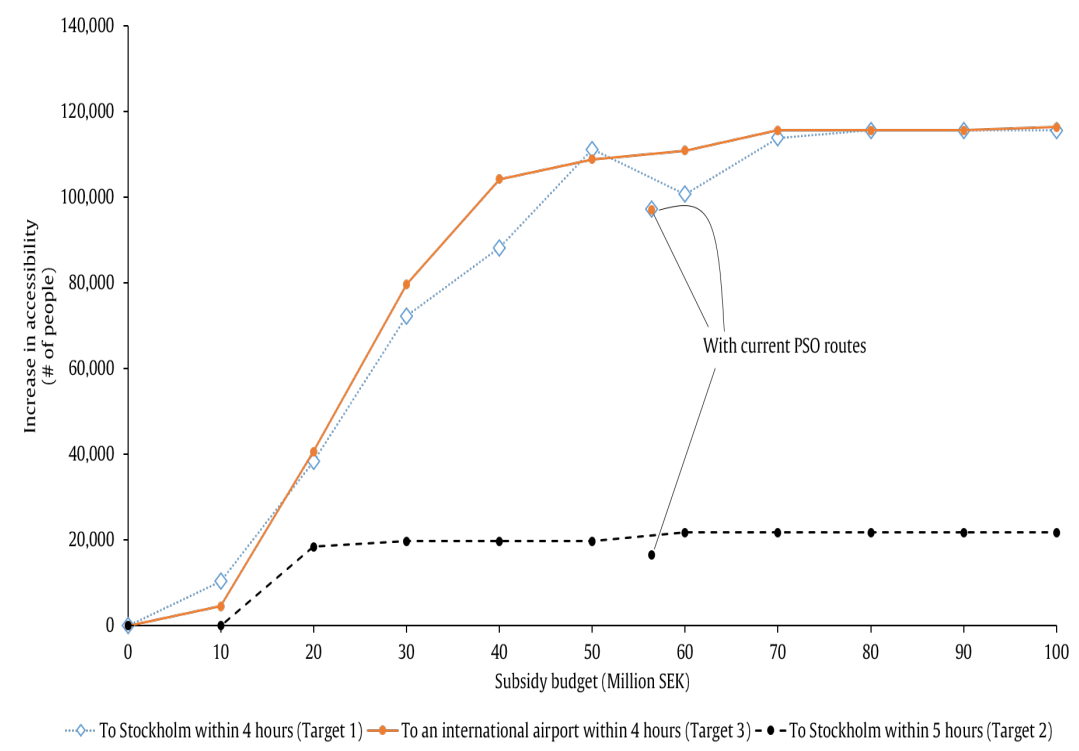

Figure 14: Improvement in accessibility for Target 5 with Stockholm-Bromma airport closed, for each PSO budget value with the current airport network

\section{Conclusion}

Using a novel method for estimating the subsidies required for new PSO routes, and an optimisation model capable of handling multiple criteria, targets and budgets, we analyse the Swedish PSO route network. The results show that most of the Swedish population already have good accessibility, with respect to the studied targets.

The model suggests a new network with improved accessibility, at a lower subsidy cost. The required subsidies for the new network is lower because it consists of less number of routes, and more one-stop routes compared to the current Swedish PSO network. One-stop routes generally require less subsidy than non-stop routes (because of the possibility to pick up more passengers and get more revenue) and with the right configuration, they can serve more people. From an operations perspective, less number of routes and more one-stop routes could cause capacity problems in the the PSO network. In the worst case, larger aircraft than those currently in use would be required to 
serve the higher demand that is consolidated in a few one-stop routes. However, the current average load factor of $60 \%$ suggests that the same aircraft sizes as today would be sufficient to also serve the consolidated demand.

There are several possible explanations as to why the routes suggested by the optimisation model improve the accessibility more than the current routes. First of all, we only consider two of the eight the criteria used by Trafikverket. Although, these two criteria can be considered as representative of the other six criteria (see Section 2.2), it is reasonable to assume that the accessibility for some population centres might be worse when studying additional criteria, giving incentives to add routes that are not detected by our model. Secondly, some of the routes that can be used by the model might induce set-up costs, which are not considered. Still, considering the two accessibility criteria and the assumptions used for analysis in this paper, the results suggest that it might be possible to improve the accessibility significantly using a smaller budget than today.

The model can be used by managers at transportation authorities to make airport location decisions as depicted by Scenario 2 in Section 3.2. For example, the model would indicate to the managers that the closure of Stockholm-Bromma airport in 2022 would impair the accessibility to Stockholm city for parts of the population. To rectify this, a subsidised route to Stockholm-Arlanda is suggested by the model. Of course, the final decision should be based on whether the demand on the lost commercial route was thin enough to be considered for subsidisation. Otherwise a commercial route to Stockholm-Arlanda is probably a better alternative.

When using the model to analyse the system, it is helpful to study solutions for individual targets, as well as solutions for multiple objectives. While these sometimes coincide, in other cases, they provide insight into the system, and show how the PSO routes can help to improve the accessibility in different parts of the country. Although the model is used in a case study of Sweden, the flexibility demonstrated by being able to consider different targets (i.e., accessibility to airports and/or capital city, and target travel times) and scenarios means that it should be possible to apply the model, and the cost/demand estimation method, to other countries with subsidy schemes in air transportation, for example PSO schemes in other EEA countries and the EAS scheme in the USA.

To summarise the managerial implications of the results, it may seem excessive to spend millions improving the accessibility for a relatively small portion of the population. However, distributing an annual budget of 50 million SEK over the approximately 100,000 people who will benefit, gives an annual cost of about 500 SEK (corresponding roughly to 50 Euro) per person. This might be viewed as a rather small compensation for the lack of societal services that often are distant or missing in these communities. The results indicate that one-stop routes add better accessibility for a lower subsidy, compared to non-stop routes. They however also bring longer travel times and additional inconvenience for the passengers which means that less people will use them. Thus, there is a tradeoff that has to be made by Trafikverket whether to serve more municipalities, or provide a better accessibility to a smaller population.

While the optimisation-based decision support tool developed in this study can be used to evaluate subsidy schemes in air transportation, it can still be improved through further research. For example, more detailed flight scheduling and cost modelling would increase the value of the information that can be produced using the model. It would also be interesting to rank the different criteria of a subsidy scheme based on the social benefits; this rank could also be used to compare the subsidy schemes of two or more countries.

\section{References}

Battersby, B., Oczkowski, E., 2001. An econometric analysis of the demand for domestic air travel in australia. International Journal of Transport Economics/Rivista internazionale di economia dei trasporti , 193-204.

Belobaba, P., Odoni, A., Barnhart, C., 2015. The global airline industry. John Wiley \& Sons.

Bråthen, S., Eriksen, K.S., 2016. Regional aviation and the PSO system-Level of Service and social efficiency. Journal of Air Transport Management . 
Brown, S.L., Watkins, W.S., 1968. The demand for air travel: a regression study of time-series and cross-sectional data in the us domestic market. Highway Research Record .

Bubalo, B., 2012. Social costs of public service obligation routes—calculating subsidies of regional flights in norway. NETNOMICS: Economic Research and Electronic Networking 13, 125-140.

Cunningham, L.F., Eckard, E.W., 1987. US small community air service subsidies: essential or superfluous? Journal of Transport Economics and Policy , 255-277.

DoT, US, 2009. What is Essential Air Service (EAS). Office of aviation analysis, US Department of Transportation .

EU Regulation, 2008. No 1008/2008 of the European Parliament and of the Council of 24 September 2008 on common rules for the operation of air services in the Community(Recast). EC, and amending Regulation (E. Luxembourg: Official Journal of the European Union, 31 October 2008, L293.

Flynn, J., Ratick, S., 1988. A multiobjective hierarchical covering model for the essential air services program. Transportation Science 22, 139-147.

Fridström, L., Thune-Larsen, H., 1989. An econometric air travel demand model for the entire conventional domestic network: the case of norway. Transportation Research Part B: Methodological 23, 213-223.

Google Flights, 2019. Departing flights. URL: https://www. google. com/flights\#. accessed 2019-01-30.

Grubesic, T.H., Wei, F., 2012. Evaluating the efficiency of the Essential Air Service program in the United States. Transportation Research Part A: Policy and Practice 46, 1562-1573.

Kopsch, F., 2012. A demand model for domestic air travel in sweden. Journal of Air Transport Management 20, 46-48.

Lian, J.I., Thune-Larsen, H., Draagen, L., 2010. Evaluering av anbudsordningen for regionale flyruter. Transportøkonomisk institutt.

Marler, R.T., Arora, J.S., 2010. The weighted sum method for multi-objective optimization: new insights. Structural and multidisciplinary optimization $41,853-862$.

Matisziw, T.C., Lee, C.L., Grubesic, T.H., 2012. An analysis of essential air service structure and performance. Journal of Air Transport Management 18, 5-11.

Morrison, S., Winston, C., 2010. The economic effects of airline deregulation. Brookings Institution Press.

Openflights.org, 2018. Airport and airline data 2018. URL: https://openflights.org/data.html. accessed 2018-0130.

Özcan, İ.Ç., 2014. Economic contribution of essential air service flights on small and remote communities. Journal of Air Transport Management 34, 24-29.

Pita, J.P., Adler, N., Antunes, A.P., 2014. Socially-oriented flight scheduling and fleet assignment model with an application to Norway. Transportation Research Part B: Methodological 61, 17-32.

Pita, J.P., Antunes, A.P., Barnhart, C., de Menezes, A.G., 2013. Setting public service obligations in low-demand air transportation networks: Application to the Azores. Transportation Research Part A: Policy and Practice 54, 35-48.

Statistics Sweden, 2017. Localities; areas, population. URL: https://ww.scb.se/en/finding-statistics/ statistics-by-subject-area/environment/land-use/localities-areas-population. accessed 2017-0405 .

The Great Circle Mapper, 2019. Air distance \& flight time calculation. URL: https://www . greatcirclemapper .net/. accessed 2019-01-30.

Trafikverket, 2013. Flygutredning 2015-2019. techreport. Trafikverket.

Trafikverket, 2017. Flygutredning 2019-2023. Utredning inför beslut om allmän trafikplikt. Technical Report. Trafikverket.

Transportstyrelsen, 2018. The Swedish Transport Agency statistics for all Swedish airports (state, municipal and private) with scheduled and charter traffic. URL: https://www.transportstyrelsen.se/sv/luftfart/Statistik/ Flygplatsstatistik-/. accessed 2018-01-30.

TravelTime platform, 2019. The documentation for Travel Time API V3. URL: https://api.traveltimeapp.com/. accessed 2019-01-30.

Williams, G., 2010. European experience of public service obligations, in: Air transport provision in remoter regions. Ashgate Publishing UK.

Williams, G., Bråthen, S., 2012. Air Transport Provision in Remoter Regions. Ashgate Publishing, Ltd.

Williams, G., Pagliari, R., 2004. A comparative analysis of the application and use of public service obligations in air transport within the EU. Transport Policy 11, 55-66.

Wittman, M.D., 2014. An Assessment of Air Service Accessibility in US Metropolitan Regions, 2007-2012. Technical Report. MIT International Center for Air Transportation. 